\title{
On insecurity as a public issue
}

\author{
Luiz Eduardo Soares ${ }^{1}$
}

Public security should not be seen as simply an empirically measurable phenomenon, but rather as a process of stabilization of positive expectations. This thesis has consequences that I believe are relevant to empirical analyses in criminology, to the identification of the challenges that must be confronted by public administrators, to a sociological understanding of the problem of insecurity, and to an understanding of what might be called the political economy of risks in contemporary societies. The analysis presented below is the result of participant ethnographic observation as a human-rights activist in Rio de Janeiro in the eighties and nineties and as a researcher in violence and crime, and completed in the late nineties in my 500-day period during which I held top posts in the area of public security in Rio de Janeiro State, first as Undersecretary and later as Coordinator of Security, Justice, Civil Defense and Citizenship.

\section{What is insecurity? First delimitation of the problem}

Insecurity is the generation of negative expectations associated with quite disparate experiences, ranging from being the victim of a crime to being denied fundamental democratic rights $\mathbf{B}$ as is the case in the favelas of Rio de Janeiro, where the population is subjected to the two-pronged despotism imposed by heavilyarmed drug dealers and corrupt policemen (more about which later).

\footnotetext{
${ }^{1}$ Anthropologist and Political Scientist, professor at the Iuperj. Contacts with the author: LuizEbmSoares@aol.com. - I would like to thank Prof. Lena Lavinas for inviting me to write this paper and present it at a seminar organized by the WTO in Geneva, 28-29 May 2001.
} 
In the generation of negative expectations there are additional dimensions that have to do with imponderable and elusive aspects of insecurity that are at least as relevant as the risk rates that can be calculated on the basis of crime statistics. But it is only for the analyst that there is a discontinuity on the plane of elusive and ubiquitous factors. In the everyday lives of individuals they are interconnected by metonymic contiguity, and they are dispersed according to a psycho-symbolical logic of associative extension governed by specific cultural languages. What follows is a brief description of these elements and of the institutional agencies involved:

(1) Family structures that are institutionalized and reinforced by traditional values tend to ease the anxiety brought about by uncertainty, which is inevitably associated with imaginary anticipation of the future (regardless of any other forms of suffering, neuroses and pathological effects that may be caused by such structures). Uncertainty and anxiety are aggravated by factors external to individuals' biographical backgrounds, such as the corrosion of the conventional norms that govern conjugal and family behavior, the assertion of new rules and values not yet sufficiently introjected $\mathbf{B}$ in other words, changes in family structures: new ways of organizing people's affective lives, sex lives and reproductive practices; changes in gender roles; changes in intergenerational relations; changes in parental roles. The expansion of arrangements that are associated with single-parent households and that encourage solitary trajectories; the denaturalization of "blood ties," which trivializes the exclusion of fathers from families and consequently devalues patrilineal descent $\mathbf{B}$ this entire process, in a cultural context that still prizes genealogical bilateralism and cultivates traditional family values, tends to increase the anxiety caused by the symbolic prefiguration of death crystallized in the painful experience of uncertainty.

(2) As traditional forms and rules are emptied of meaning, the biographical and family rituals that mark and symbolically control the passage of time correspondingly lose their emotional attractiveness and evocative power. I refer to the celebrations, directly or indirectly associated with religious feasts or national holidays, that are appropriated and given new meaning in the private sphere, and that regulate the passage from one stage of life to the next, generating narratives that organize the collective memory of families, which in turn fosters the dynamics of identity.

(3) Religious beliefs, behaviors and rituals make up one of the most important cultural codes for the symbolic control of uncertainty. Though the ultimate disappearance of religions has been long prophesied, contemporary experience has demonstrated the vitality of religious languages, even if conventional forms 
are not necessarily adhered to. However, given the individualistic nature of many of the new creeds that have swamped the market for religious goods, it appears that permanent religious communities, with territorial bases and regular meetings, have lost ground. It then seems plausible to conclude that religion's power to mitigate anxiety has decreased with the weakening of sociability and collective rites, which are potentially able to control anxiety, replaced by private and individual beliefs and rituals.

(4) One of the virtues of everyday sociability is the sharing of anxiety control. The symbolic resources for this control are various, from daily greetings and autonomic comments about the weather and the passage of time to civic participation in common activities. There is also the social delimitation of time by means of the iteration of agricultural work, gardening activities, waiting for the bus or sorting garbage. But community life goes beyond the sphere of the neighborhood. The working community and the political community have played major roles as organizers of life histories and collective time. Today they tend to lose their prestige and practical relevance as jobs become precarious and are increasingly reduced to provisional part-time tasks. In this context, one's working history and political commitment are displaced from their central positions due to the decline of civic and political culture and the willingness to participate.

(5) The crisis of nations as cores of identity repertoires points to the crisis of national communities, which in turn implies the erosion of languages that have traditionally served the symbolic process of reducing uncertainty and providing symbolic control of historical time by means of shared beliefs, memories and rituals.

(6) Another important factor in the increase of anxiety caused by uncertainty is the intensity, pace and scope of technological development (particularly in communications and genetic engineering). Technological development implies on the one hand more control over uncertainty and reduction of indetermination, but on the other hand it also means a threat to subcultures, their bodies of knowledge, their practices, their social devices and rituals, their conventional technologies and their languages. In the contemporary world, the continuous flow that characterizes the migration of financial capital is a source of uncertainty, which to a certain extent now plays the frightening role assigned to nature in the past.

In such a context, the Other, any kind of otherness, particularly in its most radical form Bthe representation of death, that is, the mark of finitudeB as embodied in the unpredictable future and the unknown foreigner, must be controlled and stigmatized in order to reduce the uncertainty associated with the meaning of both 
the future and the unknown (single or collective) character. Time, understood as an unstoppable and unpredictable flow, must be regulated, tamed, disciplined and controlled through obsessive rituals and their repetitive interventions, the most obvious form of which today is perhaps drug addiction.

On the basis of this diagnosis, I do not propose a conservative and nostalgic revival of traditional forms, but rather the creation of positive resources for reducing the anxiety caused by the growing everyday experience of the negative dimension of uncertainty.

Violence and, more specifically, crime are no more than particular variants of insecurity, the diffuse, protean and ubiquitous nature of which calls for a multidisciplinary approach and multisectorial interventions involving both the state and civil society. The object of democratic and civic-minded social policies and initiatives should be, I believe, the reduction of the suffering and damage indirectly caused by societies' desperate effort to increase control of what is unknown and unpredictable. Insecurity is an ethereal and evanescent subject, but this does not mean that it is unrelated to objective facts, tendencies and risks on the most diversified planes of collective existence. That is why it is convenient to define it as instability of expectations or stabilization of negative expectations. Let us turn to a real-life example.

$* * *$

To begin with, consider the criminal episodes or incidents interpreted as relevant to the semantic, moral and affective space associated with victimization. Facts that may be considered criminal often overstep this qualification, or else evoke it, refer to it or approach it in the interpretations of some or all of the actors involved, even though they may not correspond exactly to such a classification. However, the difficulty is not restricted to the possibly contradictory variety of interpretations, which are supplemented, though not exhausted, by the supposedly technical reconstitution by experts, physicians, investigators, journalists, members of NGOs and politicians, on different levels and with different motives. One must also take into account the official disappearance Bwhich, however, does not imply subjective or social disappearanceB of facts that are experienced, remembered and discussed by social groups but are never even connected to the dynamics of formal acknowledgment, of police and juridical deliberations and procedures, for the simple reason that they are never reported to the institutions responsible for the keeping of records of criminal occurrences. 
As to the variety of interpretations, the different descriptions of facts produce a polysemous repertoire or a constellation of meanings, ordered into distinct vocabularies, following differentiated moral and taxonomic categories that are rife with ambiguities. What has happened? What may be singled out as significant in the event observed and reported? Is it an event, an actor or a setting? What actors are involved in what setting, in what context, having what events, what common history as backdrop? For each case, what are the motives, desires, interests, fantasies and strategies? Which moral categories are applicable? What stigmata are projected, and which penal coding reorganizes narratives in what way, disclosing what underlying unit? How are chains of testimonials interrelated and edited in police reports? Popular subcultures and their political and moral lexicons are not juxtaposed to the penal code and the police subculture, which makes it difficult to translate or formalize the record that designates the "episode" as a police occurrence.

Some figures may help underscore the social relevance of the aspects that are perhaps most expressive of the least visible dimension of this problem: the Military Police of Rio de Janeiro State answers an average of 20,000 telephone calls daily, 80 percent of which have to do with occurrences classified as noncriminal, including all sorts of conflicts and situations involving different kinds of physical and social risk. This means that about 16,000 police interventions are the object of informal interpretive negotiations and remain invisible, submerged, as it were, never rising to the plane of observation, evaluation and focusing of public-security policies. On the other hand, about 80 percent of larcenies and 75 percent of robberies in Rio de Janeiro City are never reported to the police because the victims are afraid of involvement with the two police forces (the Civil Police, responsible for investigation, and the Military Police, in charge of enforcement and prevention) or because they have no trust in the competence of the police.

Another type of incident is revealing of the multidimensional nature of experiences directly or indirectly associated with violence, crime and public insecurity. Here is a revealing example: early in 1994 Rio was dominated by fear and by a generalized feeling of powerlessness. Society was still trying to come to grips with two particularly traumatic tragedies: the massacre of children and teenagers at the very doorstep of the Candelária Church, in the downtown area, and the slaughter of various working-class families, which took place when the victims were asleep in their own homes, in the Vigário Geral shantytown; these crimes were all perpetrated by policemen. In such a charged climate, a middle-class white lady from Tijuca, a conservative neighborhood, gets in the elevator of an office building downtown. She is alone. She pushes the button for the twentieth floor. On 
the second floor the elevator stops and a young black man, shabbily dressed, steps in. The woman immediately realizes that the time has come for her to face what so many of her friends have already experienced, what she has been anticipating every day whenever she ventures to leave her apartment and expose herself to criminal attacks. She has finally met the foe she has long been fearing. Her time has come. She stands face to face with him. The vague fear she has been feeling now crystallizes as the paralyzing anxiety of panic. She stands frozen, her mind gripped by terror. At any moment the attack may come. The seconds drag on and on. It occurs to her that perhaps she should press the button for the next floor, but she fears that any movement might have the effect of hastening the aggression. She fervently prays that someone will walk into the elevator on the next floor, but at the same time fears that the appearance of a third person may spark off a violent scene. Her hands are cold and trembling. She can barely see. Terror makes it hard for her to breathe. Time has stopped in its tracks. Suddenly the elevator stops. The young man says "Good afternoon," and calmly walks out of the elevator.

That evening the lady from Tijuca phones one of her friends. "You can't imagine what happened to me this afternoon: I barely escaped being mugged. This town is really becoming impossible. It's unbearable. What next? You can't imagine what I went through."

An initial interpretation of this episode Btrue enough as far as it goes, but insufficient $\boldsymbol{B}$ would underscore the force of racial prejudice and the projective effects of stigmatization, reinforced by the loss of credibility of the state and its institutions, as well as by the context of generalized uncertainty that magnifies the potential risk of any contact with strangers, or of the very experience of sociability. I would like to emphasize, however, the relevance of a different interpretation, which might be stated as follows: even though there was no robbery, no aggression of any kind, no crime whatsoever from a positivistic viewpoint, the experience of suffering caused by an inevitable and imminent attack was quite real; it was incorporated into that particular lady's life and memories, kept her from sleeping that night, led her to take a tranquilizer and left its mark forever on her. The anticipated criminal fact never took place. It was just a case of panic brought about by racism and class prejudice. Nevertheless, the pain of those interminable seconds was quite real, and it had the effect of adding to the intersubjective chain that gave impetus to the culture of fear $\boldsymbol{B}$ that is, the instability of expectations, or rather a perverse and selffulfilling stability of negative expectations.

This is why those who interpret, research and study social phenomena or are responsible for public-security policies cannot afford to downplay the importance 
of the interplay of subjectivities, of collective perceptions and expectations, lest they lose sight of a substantial part of their object. It is necessary to acknowledge the multidimensional nature of violence, crime and the experience of collective insecurity, which, as I have stressed, involves a wide variety of other factors, such as changes in family structures, changes in community sociability, the shrinking of political, civic and national feeling, and changes in the experience of employment and work that have replaced the continuous and unitary sense of career with the reductive experience of work as discrete tasks. But since my major purpose in this paper is to underscore the relevance of violence and crime $\mathbf{B m o r e}$ specifically, of criminal violence as a factor in generating fear, uncertainty, social anxiety and insecurity in the widest sense $\boldsymbol{B}$ an in-depth examination of the criminal fact is in order. To do this, I would like to open the "black box," to break the unity evoked by the category "criminal fact" so as to describe the various components that make up its complex and multidimensional structure. Once we understand the conflicting heterogeneity of what is collectively known as a "criminal fact," we shall also understand that any public policy aimed at it must take into account this multiplicity of levels. If our purpose is to draw a parallel between the insecurity brought about by the changes taking place in the world of labor and the insecurity caused by crime, it is indispensable to focus on the plurality of levels involved in the making of "criminal facts." Only in this way will it be possible to denaturalize "crime" and "violence," contextualizing them without neglecting or underestimating them.

\section{Deconstructing "violent crime"}

The following elements are important for the makeup of the general situation which is the object of the interpretation or anthropological redescription I propose: (1) the criminal episodes or incidents seen as relevant to the semantic, moral and affective space associated with victimization; (2) their spontaneous editing carried out by individual and collective perceptions; (3) the narratives derived from criminal episodes that become autonomous and have an impact on social imagination and the intersubjective economy of affects; (4) the institutional interventions that classify these same criminal facts and circumscribe them operationally and symbolically, investing them with new meanings and submitting them to specialized chains of causality (on both the hermeneutic and the practical planes), such as police forces, hospitals and forensic-medicine institutes; (5) the selective focusing and reconstruction of facts carried out by the press, the spectacular intervention of television, the dramatic and critical rhetoric of radio; (6) the series of political and administrative procedures of public-security authorities and government; (7) the 
reactions of NGOs, opinion-research institutions and political parties, which question the government and try to find shortcuts in their communication with public opinion. These seven factors interact with and modify one another, generating contradictory, dynamic and multidimensional combinations of practices and meanings, the effects of which correspond to evaluations that lead to expectations and orient future behaviors, producing positive or negative self-fulfilling prophecies. In addition, it should be stressed that each of the factors mentioned above incorporates various spheres of social action, ruled by particular logics and interests and limited by specific rules. Any simplification, such as applying the public-private dichotomy to the continuity of events and the flow of rereadings of events, would fail to account for the complexity involved in each sphere included in the brief enumeration of factors above.

$$
* * *
$$

(1 and 2) It is worthwhile to reflect a little on the editing of "criminal episodes" spontaneously elaborated by individual and collective perceptions. In order to work scientifically with crime-related empirical data one must consider them very carefully and critically, because Bquite apart from the problems associated with the quality of police records $\boldsymbol{B}$ so-called "facts" are interpreted by local communities or the random groups of people who witnessed them or heard descriptions of them and retransmitted them. Of course, victimization surveys may attain a high degree of objectivity when they include questions about specific crimes. However, such crimes are hardly likely to amount to the entirety of incidents and interpretations that make the population uneasy. A situation perceived as suspicious and frightening may give rise to experiences of social friction, to encounters that generate perceived threats, because of racial and social stigmas, for instance, even when no violent facts or criminal episodes are involved. Here is a typical situation: crossing an illlighted and dirty tunnel for pedestrians may in itself be an experience as frightening as an actual minor experience of victimization, say, of petty larceny. Walking by a group of loud strangers at a deserted street corner may generate feelings of fear and anxiety that leave marks equivalent to those left by victimization. When family members, friends are neighbors talk about the city and its fears, to actual episodes are added "quasi-episodes" $\boldsymbol{B}$ that is, "noncriminal facts" that generate fear or threatening situations. The result of such heterogeneous social perceptions may add up to a general situation of despondency. This should not be seen by experts as the consequence of a lack of accurate information or as merely the product of projected prejudices and stigmata, requiring demystifying and critical responses from public-security authorities. I believe it would be far more effective to respect 
such socially experienced suffering and to take these perceptions seriously, because they do not simply fade away when confronted with the "truth" revealed by the authorities. In other words, installing better lighting in the dark tunnel and the deserted corner is better than criticizing the population's psychological instability, demanding that people report their own experiences in a more balanced away, or publicizing favorable statistical data.

(3) It is important to take into account the narratives that, originating in criminal episodes, later take on a life of their own and come to have an impact on social imagination and on the intersubjective economy of affects. Like the morbid fantasy experienced in the elevator and the mixed-up collective perceptions of actual crimes and frightening experiences that add up to a negative global image, it is necessary to consider the effects of the autonomization of narratives that have a factual empirical basis but have become disconnected from their sources and been converted into a general negative perception of the experience of sociability. Because of a single case of rape in the West Zone of Rio de Janeiro in the early nineties, all crimes against women were interpreted by the local population as probable attempted rapes. This had the consequence of changing behaviors and routines in families, in local trade establishments and schools for several months, as well as multiplying rape reports that were never certified.

(4) It is indispensable to keep in mind that the criminal facts which are the concern of public-security experts and authorities are filtered by the institutional interventions that classify and circumscribe them, operationally and symbolically, investing them with new meanings and submitting them to chains of cause and effect. The victim is a patient in the emergency room of a hospital or a dead body undergoing autopsy in the morgue before he or she is officially classified as the victim of criminal aggression in accordance with the penal code in the records of a police station. This diversity of technical and institutional functions and procedures may spark a conflict over the definition of the meanings of events, a conflict that tends to become more heated when the links between institutions are disorganized.

(5) We are all aware of the strategic importance of the media when it comes to focusing on themes, dramatizing and setting the tone for the interpretation of certain problems of social life. We know that the media participates in the process of setting the priorities of public issues, and that the play of emphases and shifts in collective attention changes social perceptions. In Rio de Janeiro, for instance, if the media gave equal attention and equally emotional treatment to violent crime in fashionable neighborhoods and low-income areas, the correlation of political for- 
ces would probably undergo a radical change. Crime, as it is depicted by the media, is both the representation of the experienced phenomena, according to a specific selective bias and a given critical emphasis, and a source of collective orientation for a prospective reading of social life.

(6) The performance, the discourse and the initiatives of public-security authorities are relevant factors, operating as alternative sources, as antagonists of the dominant discourse of the media, or as interlocutors that interfere in the hermeneutic orientation disseminated by the media. In addition, their administrative and political decisions have an impact on the collection, processing and dissemination of the "primary" data on crime, which obviously leads us to denaturalize, relativize and contextualize the primary character of these data and their informational consistency.

(7) Human-rights activists, members of NGOs and researchers are also players in this game of production and diffusion of information and meaning, generating adaptive reactions in the other players and changing the general conditions under which the phenomena associated with public insecurity are appropriated, analyzed and converted into tropes of political rhetoric or motivation for social action. There is no such thing as an entirely uninvolved observer who is in touch with the pure facts of the case. Administrators do not act on criminal dynamics guided by purely technical criteria, their developments, their migrations and their immediate or structural causes. Each move by each player alters the field, the conditions of observation and the logic of the production of events and meanings. That is why my conclusion is that researchers' studies and administrators' interventions should appreciate the multidimensional and interactive nature of this complexity.

\section{$* * *$}

When all these factors are articulated, the most diverse results are produced and variously computed in official statistics, assuming distinct meanings for local populations, eliciting different reactions from authorities and a wide range of focusing angles from the media, social perceptions and political reactions. For instance, a death caused by police action in a favela may be defined by the community as a crime (extermination, revenge, extortion from drug dealers or elimination of potential witnesses), which may lead to violent and emotional protests resulting in the destruction of public equipment, the burning of buses, and the occupation of streets giving access to the favela in question. Officially, the death may be defined as an "act of resistance" Bthat is, legitimate self-defense by the police in an authorized operation $\boldsymbol{B}$ and this classification itself may be submitted to a number of different 
treatments throughout its trajectory in the bureaucracy of the law, beginning as "fatal victim of a shot from a firearm" (a synonym for murder in the parlance of coroners), changing to "death demanding investigation" in the police report and finally being transformed into an "act of resistance" by arrangement with the Security Secretariat. The death may get a brief notice in a few newspapers or magazines, together with the statement of the official line or with its reinterpretation as a sort of "employment-related accident," or else the popular rebellion may be focused on as vandalism, which in turn may lead the authorities to announce more drastic repressive measures against demonstrations. Other papers may concentrate on police brutality and mention accusations of corruption to explain the fact. The political strength and influence on public opinion of a particular publication sensitive to the issue of police violence may force authorities to reconsider classifications that have the effect of protecting the police and to reaffirm an official promise to investigate the crime "rigorously." Often interpretation of facts amounts to a veritable battlefield where different meanings and political implications clash, together with contrasting technical categorizations and competitors in the market for news, the relevance of which depends on the interpretations associated with each.

$* * *$

In short, the seven factors mentioned above are relevant to the production of what may be called the field of public security, and they change their quality according to the context in which they take place and the magnitude of the problems involved. That is why it is necessary to describe the present Brazilian context, focusing on the specific but also exemplary case of Rio de Janeiro. I believe such a description will contribute to an elaboration of concepts of security and insecurity on the basis of which we can formulate proposals of basic security for all.

\section{What is insecurity? Second delimitation of the problem}

Perhaps it would be wise to concentrate on a specific locus and establish empirical and historical bases for the insecurity I have in mind. In the case of Rio de Janeiro, it must be acknowledged that there is a multiplicity of experiences of insecurity. The view provided by crime data is perhaps imprecise but nevertheless indicative of the importance of the dynamics of crime, which lead to social perceptions that have made violence a major topic in the public agenda. But such data cannot by any means convey the fear, or the different ways in which fear is experienced by the various social classes, corresponding to their various forms of life. Special attention must be given to the case of Rio de Janeiro's favelas. About 
$1,200,000$ people live in approximately 600 shantytowns, subjected on a daily basis to the regime of terror imposed by the two-pronged despotism of drug and arms dealers and corrupt policemen. Before examining the situation of favelas, which is by far the most serious problem, it will be useful to examine the general situation of the city.

In Rio de Janeiro, recent surveys have shown that insecurity Bdepending on the time when researchers do their fieldworkB is the first, second or third major concern of the population (the others being unemployment and health care). The figures explain why this is so: in 1998 there were 58.98 lethal crimes per one hundred thousand inhabitants; in 1999 there was a very slight, almost unnoticeable decrease to 58.21. By lethal crimes I mean all crimes causing death, including robberies, rapes and kidnappings followed by the death of the victims. In the Brazilian criminal code these incidents are not counted as murders, since in them death is a consequence of acts oriented towards different goals. It is irrelevant to our present purposes whether or not the Brazilian code is sensible, reasonable, or wise. From the point of view of the population, all such crimes are killings and should be included in a single broad, all-encompassing category. What is meaningful about them is the fact that they have the same deadly outcome. If we look at intended homicides alone the overall picture will not change. The numbers are equally shocking and seem to suggest that an undeclared civil war is going on: in 1998, in the state of Rio de Janeiro, there were 47.26 intended homicides per one hundred thousand inhabitants; in 1999 there were 46.39. In the city of Rio de Janeiro alone 2,332 people were killed with firearms. Again, there was a slight and unnoticeable drop. Both drops were short but not necessarily negligible. They clearly pointed to a profound change that was taking place on several levels, a change most noticeable in an impressive 35.52-percent decrease in police killings. ${ }^{2}$ There were changes in the institutional mechanisms of internal affairs and in the system of policeperformance assessment, and an ombudspersonship was created. Mostly, there was a basic and radical change in the general direction of public-security policies, which stemmed from the new government's efforts to combine police effectiveness with respect for human rights. A new state government supported by a left-wing coalition was inaugurated on January 1, 1999. But that is not the point here.

\footnotetext{
${ }^{2}$ I myself supervised the process of collection and elaboration of these data, taken from reports of the Rio de Janeiro State Secretariat of Public Security.
} 
The situation seems even more dramatic if we analyze the effects of violence solely on young people. No less than 87.2 percent of those in the 15-to-19 age bracket who died in 1999 were victims of external causes, meaning they met a violent death of some kind, whether in a traffic offense, a random police shooting in a shantytown, a shootout between drug dealers, or a murder. Fifty-nine percent of teenage victims of external causes were killed with firearms. In 1999 there were 93.3 intended homicides per one hundred thousand adolescents in 15-19 bracket in the city of Rio de Janeiro, where there also were 104.3 homicides per one hundred thousand youngsters in the 20 -to-29 age range. ${ }^{3}$

Empirical studies as well as police investigations pinpoint 1988 as the turning point in the crime escalation, particularly in homicide rates. It is easy to understand why. That was the year when arms trafficking joined drug dealing and set up a number of unstable local coalitions, fighting one another over the control of territories and markets.

Fights between criminal gangs are a positive sign of underdevelopment and disorganization, but they also imply a higher degree of uncertainty and insecurity for innocent people, who face severe risks for just happening to live in a gangdominated neighborhood, for instance. To state it briefly: lack of organization in the criminal world usually means a higher risk of struggle, violence, killings, and victimization of innocent people. On the other hand, disorganization of the criminal world is a good sign from the point of view of law-enforcement agencies. Therefore, fewer deaths and killings do not necessarily mean that criminals are under control or have become less powerful and dangerous. Sometimes, paradoxically enough, the meaning is precisely the opposite.

Since 1988, it has become almost impossible to distinguish between drug dealers and arm traffickers, and the favelas have been increasingly dominated by heavily armed gangs. Of course, their main sources of financial support do not live in the hillside shantytowns or in the poor neighborhoods of the metropolitan periphery. There are links between the rank-and-file local bandits and traffickers, who are quickly and easily replaced whenever killed by rivals or arrested by a police squad, and the affluent professionals, experts in money laundering, who operate computers and are gifted enough to enjoy the benefits of globalization and meet its requirements. But the latter live away from the favelas and profit from the impunity granted to members of their class in Brazil.

${ }^{3}$ Figures presented by Ignacio Cano in the report Perfil das armas vendidas a brasileiros no Paraguai, published by Iser in July 2000. 
In 1995, almost 500 people were killed by the police in Rio de Janeiro State. That year all 19,000 U.S. police departments together accounted for the same number of deaths. This is why I stress the importance of the 1999 decrease in police killings. Such killings are caused by five major factors: (1) the hostility of traffickers who will not shrink from confronting police forces to resist arrest; (2) the deficiency of police training in using and $\mathbf{B}$ more importantlyB refraining from using firearms; (3) the inadequacy of police strategies, due to flaws in police management and institutional organization; (4) the incompetence of police investigation, because torture is forbidden by law and can no longer be relied on as an ordinary technique, although in actual fact it occurs much more frequently than educated middle-class people suspect; (5) finally and most importantly, police corruption and involvement with local gangs.

There are different kinds of involvement: policemen can be full-fledged members of gangs, with all the costs and benefits associated with this status; they can act as outside dealers, selling weapons and drugs seized somewhere else; they can sell freedom and the possibility of survival to suspects or even to innocent, mostly African-Brazilian poor people, picked at random, kidnapped and threatened with death; or they can sell protection to traffickers by providing them with a safe place to deal drugs, free from the risk of any unexpected police visit.

Any of these kinds of police involvement with locally organized crime can imply shootings for a variety of reasons, the most frequent of them being conflicts over prices, payments and debts.

All of these kinds of involvement with crime also imply brutality against the population of the shantytowns where drug dealers live, since random brutality is the easiest and most effective way for bad cops to impose their own conditions on the traffickers.

Whenever there is a political sign that the government will adopt a softer approach to control over police action, the economy of police corruption undergoes a quick turmoil in the patterns of exchange. There is inflation $\mathbf{B}$ the increase of prices for which cops sell protection, freedom and life. This is a rational move in the crime market, since the cost of breaking the law decreases for policemen. After all, they know as well as everyone else that anything $\boldsymbol{B}$ any brutality, any killingB can be justified when cops are supposed to be tough on crime.

Thus, the mostly African-Brazilian poor population of the favelas are oppressed by both drug dealers and corrupt policemen. They fear and hate traffickers, because 
these criminals act as tyrants, imposing on the local population strict codes that include curfews and off-limits areas. Nevertheless, they fear and hate bad cops above and beyond everybody and anything else. Police despotism is considered worse than the traffickers' tyranny for the simple reason that it is unpredictable and follows no rule whatsoever, whereas drug lords, as I have said, are predictable, since they enforce their own code $\mathbf{B}$ which, however despotic, is still a code and allows people to devise strategies of survival, as Primo Levi demonstrated in his reflections on the Holocaust. According to the testimony of shantytown dwellers, the power of corrupt cops stages a social drama of unlimited terror, given its intrinsic uncertainty.

Equally unable to fight crime in poor and rich neighborhoods, unable to provide public safety, and used as an instrument of oppression against the majority of the population: this, notwithstanding the existence of thousands of honest and skilled police officers, is the sorry state of the police force in Rio and in many Brazilian cities and states. The situation I have described shows the extent to which police institutions have become part of the problem, merging with the criminal world. For two main reasons this has a deep impact on democracy: first, many Brazilians are deprived of their rights of citizenship and the benefits of democratic institutions, such as freedom of movement, freedom of speech, freedom from the fear of being arbitrarily arrested, of being threatened, kidnapped, tortured, or killed, freedom to associate and assemble when and where they please; second, since military policemen Bthe men in uniformB are the most visible manifestation of the state's political institutions, the consequence of arbitrary police behavior is likely to be the loss of the credibility and legitimacy of the state. The crisis of public trust is a danger for democracy, and this is precisely what is now happening in Brazil, whenever policemen act as criminals. Therefore, in addition to widespread insecurity brought about by disgraceful crime rates, Brazilian society is currently facing the risk of losing faith in democracy, because of the state's inability to provide protection against the evils Thomas Hobbes once attributed to what he called the state of nature. From Hobbes's standpoint, this failure could imply a relapse into the war of all against all, unlimited destruction, chaos and death.

When we studied the Brazilian transition from dictatorship to democracy, we left out something that is still missing from our depictions of Brazil: the role of law-enforcement institutions in the construction and preservation of democratic institutions. Police forces have always thought of themselves as the guardians of the state, and have thought and acted accordingly, even before the 1964 coup d'état. 
Now it is urgent to reform the police, adapting it to the new role of protecting citizens and citizenship. But there is a task perhaps even more urgently needed: to restore trust, if some of it still remains alive. Trust is the password for hope, which is the nickname of commitment, which is the condition of participation, in the absence of which democracy will be defeated and reduced to a remote, tricky and meaningless television show.

Since trust is a positive self-fulfilling prophecy and the stabilization of expectations is what security is all about, a consistent project for police reform and a consistent set of public-security policies aiming to restore trust, accountability and political legitimacy should be, in my view, at the core of any democratic agenda for the Brazilian society of the next century.

$$
* * *
$$

However important it may be to reform police forces and devise efficient security policies that are effective and committed to the respect for human rights, there will be no significant change unless a major transformation occurs in the social situation, particularly the dramatic plight of deprived young people.

In the favelas and poor neighborhoods, the gangs recruit boys as young as ten, eleven or twelve years old. There are places and functions for boys of all ages, since the organization of the drug trade is a complex hierarchical structure; a distinction must be made between the quasi-military order and well-structured division of labor within local gangs and the lack of organization between different gangs. The potential for the recruitment of male youngsters is high because of social, economic, psychological and cultural factors. Approximately 1,200,000 people live in the favelas of the Rio de Janeiro metropolitan area. Of these, 360,000 are twenty-five or younger. Around 22 percent of the youngsters aged fifteen to twenty-five neither work nor study. This amount to about 60,000 young people who are total outsiders, deprived of the benefits of both work and education. Even worse, perhaps, we are talking about tens of thousands of youngsters who experience serious family troubles and loss. Many of them are victims and eyewitnesses of domestic violence. Quite a few are runaways from domestic hell. In other words, many of these young people feel they do not have much to lose.

I have mentioned cultural and psychological factors because drug trafficking, of course, does provide money, and much more than one could earn honestly as an 
unskilled worker, but it also offers something else, which may be thought of as meaning at least as much as pay and material goods $\mathbf{B}$ perhaps more. I am referring to a set of symbolic tools and resources that allow devastated minds to rebuild themselves. When a poor black boy walks the streets of Rio, aware that he will not be noticed, let alone helped, unless he becomes a source of fear for his fellow pedestrians, he might consider the hypothesis of carrying a weapon to make himself visible. The weapon will bear witness to his social existence, to his self-assertion as a person and a male. The ability to impose fear on others will act as a perverse shaping of his own identity. By making others uncomfortable and afraid, by becoming a threat to others, the boy will find his own damaging and self-damaging way out of social invisibility, restoring his ontological density, his otherwise shattered self-esteem. Not even Theodor Adorno would have conceived this evil twist of negative dialectics. Not even Anthony Giddens would dream of this tricky manipulation of modern reflectivity.

Therefore, for the street kids of Rio and for the boys in the drug-dealing business, carrying a weapon, particularly a firearm, is a paradoxically self-destructive strategy of psychological survival before it becomes a way of making money. In this specific environment and social context, power is the consequence of a certain set of relations and practices, as it is the condition for the psychological survival of the agent as an individual. Some girls, both in the shantytowns and in the fashionable neighborhoods, seem to respond positively, taking part in this game of seduction and conquest with the artificially empowered violent young gangsters. No gang member ever lasts long enough to benefit from any concrete power over territories or shares of the drug market. None of them will have time to make a fortune and enjoy it. None of them will survive beyond the early years of adulthood.

$* * *$

By now, I hope, the seriousness and complexity, in all possible senses and levels, of the situation I am describing should be clear. When we talk about insecurity in Rio we are talking about different kinds of practices, deeds, relationships, social misery, symbolic constellations and human pain. Crime is just one of the facts involved, and it is at the same time a symptom and a cause of further disarray. Am I saying that crime is a product of structural causes? Should what I have just said be interpreted as a defense of the thesis according to which poverty is the one relevant factor that explains violent behavior and crime? The answer is no; that is not what I mean at all. Though I am well aware of the controversial nature of any stand taken in the intellectual realm where this issue belongs, I would say that the best solution 
should be stated as follows: violence (in its broadest meaning) and crime are either related or unrelated to economic, social and cultural conditions, depending on what exactly we are talking about in each specific case, and depending on how we describe these conditions. For instance: poverty is not the same as inequality, just as misery could be understood as either necessarily connected to the lack of citizenship rights or not linked to it, which would lead to different approaches. Culture, values, symbolic languages, religious worldviews can convey resignation to material difficulties and even to social inequalities, reinforcing them, or, on the contrary, mandate rebellion and disobedience. The latter may come from an explicitly nonconformist content of cultural forms or from the simple contradiction of commonsensical orientations. At the other end of the correlation there are many different kinds of delinquent behavior B bank robberies, arm trafficking and money laundering have probably more to do with impunity, with the chances of being caught and with the perceived competence of law-enforcement agencies than with economic deprivation. For these crimes demand professional qualifications and are more likely to be associated with access both to schooling and to networks of organized criminals. On the other hand, it should not surprise us if a street kid, overwhelmed by drug addiction and lack of money, were to become a pickpocket to indulge in his habit. In this case, material conditions seem to exert an obvious role, even though the causal forces never work mechanically. There are always different possible responses to them. Particular contexts should always be considered.

Having said this, I do not think I will run the risk of being misunderstood if I say that the performance of law-enforcement institutions and the appropriateness of public-security policies can make a difference, contributing to make society and social life more or less violent, more or less threatened by crime. That is the point I intend to make, calling your attention to the consequences of neglecting it. These are the consequences for which Brazilian society, and the population of Rio de Janeiro in particular, has been paying a very high price.

\section{Right, left and public security}

\section{The case of Rio de Janeiro}

Instead of presenting the conservative and progressive views of public security in Brazil, I will summarize the history of ideological and political conflicts over this issue in Rio de Janeiro, the state in which it has been most hotly debated. This 
summary will perhaps portray more clearly and objectively dominant viewpoints on the left and on the right, as well as the new views that have arisen. Situating the struggle over ideas in its historical context will give it more density, by incorporating all the dimensions involved in a discussion that is by no means solely a question of doctrine or ideology.

In 1982, the state of Rio de Janeiro B as all the other states in the Union B held its first democratic election for governor in twenty years. Brazil, as a nation, was then still under severe restrictions and limitations, though the military dictatorship had softened the controls of censorship while still containing civil society's pressures for freedom and full political participation. Ambiguity and moderation were the key words for both the dictator's allies and the main leaders of the liberal and socialist opposition. It was in such very special circumstances that Rio de Janeiro State elected Leonel Brizola, a populist politician who had played a major role before the 1964 coup as a radical left-wing leader. Although Brizola invested all his best skills in the reshaping of his ideological character, redefining himself as a moderate social-democrat of the European kind, his inauguration meant a lot and necessarily had to bring with it radical changes in the pattern of behavior of the police. There are two police forces in every state of the Union: the Military Police, whose members wear uniforms, and which is responsible for preventive patrolling and repressive law enforcement; and the Civil Police, which works under cover and is responsible for investigation, besides running the police stations, where victims must go to report their complaints, which are collected and organized by the official records. It is not hard to understand why both police forces were at stake in the first near-free election after two decades of an authoritarian regime. They were known as the regime's guardians, the ruthless protectors of the state. They were seen by no one, not even by themselves, as guardians of the laws and protectors of the citizens. They were not trained to act as modern, civilized, democratic law-enforcement agencies. Brizola promised that the police forces would change, and change they did. Nevertheless, the change they underwent, though in a certain sense radical, was not a deep institutional reorganization, guided by new goals and principles, which would supply new methods and techniques while replacing torture and violence with intelligent, lawful and systematic procedures.

It was not easy to change institutions whose members had for decades been working as violent, single-minded warriors, targeting the usual suspects, mostly the black and the poor. This politically biased role was not invented and assigned to the police forces by the 1964 dictatorship: rather, it had been traditionally assigned to them; it was deeply rooted in popular culture and in the professional consciousness of policemen themselves. 
The only change Brizola did achieve was a provisional reduction of police brutality, the partial suppression of torture, of random shootings and killings in the favelas and low-income neighborhoods. The newly elected governor fought the death squads created by policemen and reduced their power, their freedom to act and their impunity. These efforts and achievements should not be underestimated, but they were certainly far from enough. The reduction of cruel practices implied two consequences: (1) it replaced police activity with passivity, which was by definition ineffective to fight crime and control the acts of violence that were not perpetrated by police officers themselves; (2) it left untouched the institutional sources of police brutality and ineffectiveness.

So it was that the human-rights rationale invoked by activists and by Brizola himself to justify his negative policy Bor his unwillingness to adopt any positive policy whatsoeverB the human-rights discourse rationale, I repeat, eventually became discredited in the eyes of public opinion, since it was associated with police passivity and the state's inability to enforce law and order. It did not take much for the conservative political enemies of Brizola to transform impotence and passivity into accusations of complicity with the criminals.

Civil-society organizations and human-rights activists, myself included, were unable at that time to go beyond complaints and accusations. Everyone on the left knew what was not acceptable, what should be refused and denounced, but nobody knew what to do instead. There was not a single constructive proposal in the field of police reform, mostly because we did not believe public security had any meaning whatsoever B at least not to the poor, we thought. Our progressive minds were obsessed with structural causes and blind to the seriousness of crime, which was, to us, just a symptom and a consequence. We were unable to acknowledge the unavoidable relevance of these so-called consequences in themselves. Our political adversaries were much more perceptive and skillful in foreseeing the broad meaning of the issue in its own right, and not just as a superstructural signal of something else. Besides this regrettable blindness, we, the human-rights activists and leftoriented scholars, were unable to appreciate the extreme importance of police brutality itself, almost always perpetrated against the common people. We thought our good fight was over when the dictatorship was defeated and the practice of torturing political prisoners was abandoned. Since middle-class militants were no longer the victims of crime and crimes were not political anymore, the problem of police atrocities seemed to disappear for most of us. With the exception of a few scholars, such as Paulo Sergio Pinheiro, and some NGO activists, the theme of police brutality and torture vanished from the public agenda in the early eighties. 
State violence was not an issue anymore, with the rebirth of democratic institutions. The lack of public policies combined with the negative attitude of human-rights groups paved the way for a conservative backlash.

Promising to banish violence in six months, a liberal conservative, Wellington Moreira Franco, was elected governor in 1986. In the area of public security his government was a step backwards. Whatever good had been done by Brizola was undone by Moreira Franco. The infamous death squads were strengthened, mostly in the peripheral areas of Greater Rio; police brutality increased rapidly and the "tough on crime" ideology replaced the human-rights vocabulary. Law-enforcement agencies were once more free to loosen their control over the soldiers and to be soft on police crime. The internal-affairs personnel lost power. The racist and socially biased methods of frisking suspects were reintroduced. Inevitably, Moreira Franco failed to banish violence in six months Bhe was not a magician, after allB nor did he succeed in reducing crime. The timid police reform that was in place during Brizola's term, mostly limited to a negative agenda, was completely abandoned during the latter half of the eighties, under Franco's conservative government.

In 1990, for the second time Brizola was elected governor of the state of Rio de Janeiro. Again he proposed his negative agenda as his project for police reform: once more, both police forces should learn what to avoid, what to refrain from doing, what not to do. He did not have much to say on the spread of violence and the increase of crime rates. He did not propose or implement any public-safety policy. Left-wing parties and human-rights activists mostly agreed with Brizola's view of the problem: at the time, all of them thought of crime as nothing more than a symptom of social inequalities and economic deprivation. Therefore there was nothing to be done against the escalation of crime as such. The only possible positive measures would be those that had to be taken in the field of social and economic policies. In one word: crime did not matter; the structural causes of crime were the only real issues that deserved attention, public concern and political investment. Policies for public safety were just rightist talk, conservative nonsense. But even those on the right, though acknowledging the significance of public safety, did not know what to propose or demand besides more freedom for the police to do, as they used to say, what had to be done. Capital punishment of course was also an issue for them, at least for a while, when it was necessary, for political reasons, to oppose human-rights discourse.

Full of good intentions but passive before the rise of crime, ineffective even in controlling police behavior, Brizola was defeated in 1994 and has been defeated 
many times since then. He is still paying the price for having neglected the importance of crime, which society as a whole considered crucial, as it still does. His second term became associated with images of violence. In 1993, the history of Rio de Janeiro was forever tarnished by the two tragedies I have already mentioned: the slaughter of street kids in front of the Candelária Church and the Vigário Geral massacre. Both tragedies were, to a certain extent, police reactions against Brizola's efforts to stop police brutality. It is ironic and deeply unfair that Brizola should have been the governor in charge when some of the worst police atrocities occurred. This fact alone would have been enough to bring about his political death.

Thus no one was surprised when Marcello Alencar, Brizola's former ally who had become his bitterest political enemy, won the 1994 gubernatorial election. With Governor Alencar and his Secretary of Public Security, Gen. Newton Cerqueira, old ideologies and practices came back. General Cerqueira served the authoritarian regime and was notorious for having killed with his own gun, as he himself often boasted, Carlos Lamarca, one of the most important Brazilian Communist leaders. Again, the authorities affirmed their intention of being tough on crime. Once more they went soft on police crime and stimulated police brutality, more than any previous government. Homicide rates were somewhat stabilized, but on very high levels; and life in the favelas became unbearable. Poor people became, more than ever before, oppressed by both the despotism of drug lords and the tyranny of corrupt policemen.

In 1998, the political pendulum brought the left back to power. But this time the candidate supported by the parties on the left, Anthony William Garotinho Matheus de Oliveira, shaped his own political identity on original terms. Instead of taking for granted the social roots of crime, of neglecting the need for specific policies to fight crime, he was careful to distinguish between different kinds of crime, to focus on the complexity of their connection with the social and economic structure, and was bold enough to draw public attention to a new possibility. Anthony Garotinho, whose public-security plans I had the honor to devise, was advised to affirm the possibility of combining political sensitivity to the urgency of social needs with a surprising commitment to face the challenge of public security. Because his political origin was in the left, because he was the inheritor of the socialist legacy and was deeply concerned with human-rights issues, no one expected him to face the public-security challenge squarely. The candidate also committed himself to the implementation of policies that would combine respect for human rights 
with a dramatic increase in police effectiveness. He promised a drastic police reform that would sweep away the criminals hiding behind uniforms. His proposal was based upon a three-dimensional program of modernization, moralization and community participation.

Anthony Garotinho won the election and began to implement the first set of policies for public safety and the first police reform program ever tried in the state of Rio de Janeiro. It included new methods of recruitment and training; the introduction of rational management features, such as planning and assessing procedures; the reorganization of routine procedures in police stations; the elimination of the jails that operated illegally in the premises of police stations; and the rebuilding of public assistance and investigative practices, which became part of a system of computerized data collection, analysis, mapping and information exchange. The Secretariat of Public Security created five new agencies, all of them in partnership with civil-society organizations, for the protection of women and the reduction of domestic violence, for the protection of children and adolescents, for the defense of the environment, against racism and against homophobia.

But such changes cannot possibly be easy if you are cracking down on police corruption and brutality while fighting crime at the same time. Corrupt cops can always resort to an effective weapon: they can threaten the governor, promising to destabilize public order, by means of kidnappings, killings and random shootings. On the other hand, they can produce arrests of well-known criminals and other quick results that make a favorable impression on public opinion. Aware of the possible dangers of subversion and the benefits of quick but inconsistent results, the governor decided not to face the risks of a radical confrontation and opted instead for a negotiated solution, trying to subdue the most dangerous segments of both police forces through co-option. Therefore the program of police reform was postponed and the innovative policies for public security were abandoned.

It seems that the tradition of building coalitions with the enemies within the police forces is stronger than the political will to bring about a deep restructuring of public safety. The visibility and popularity of the issue implied its overwhelming politicization, which so far has condemned it to populist manipulation. It is to be hoped that the increasing awareness of its meaning will impose solutions beyond electoral and opportunistic interests. Public safety has become a crucial issue for the future possibilities of Brazilian democracy. The divide does not oppose right and left, but barbarity and the chances of civilization in Brazil. 


\section{The theoretical and ideological debate}

As the recent political history of Rio de Janeiro makes clear, the right has always known what to do about public security: to unleash police forces like watchdogs on the "dangerous classes," setting up a cordon sanitaire around them in order to protect the middle classes and the elite. This kind of politics no longer works, because the poor population has increased too much, because democracy provides ways to resist police brutality, and also because such brutality has had the effect of degrading police institutions to such an extent that not even the elite trusts them anymore. Also, this brutality has opened up a chasm between society and the police forces, a fact that jeopardizes even the legitimacy of democratic institutions. The situation of generalized criminal violence in Rio de Janeiro and Brazil today is the result of a model of wild development and wild security policies. Conservatives themselves are coming to the realization that the old methods no longer work. The left, on the other hand, is beginning to awaken from its dogmatic sleep and to understand that accusing, denouncing and criticizing is not enough: it is necessary to put forward constructive and viable alternatives. The left is beginning to realize that even if it is still an urgent priority to implement policies that will have the effect of radically changing the socioeconomic structures of Brazilian society, this is simply not enough as a response to the issue of public security. There are specific characteristics and specific dynamics involved in this issue that require specific public policies.

While Brazilian leftists are slowly, carefully and hesitantly adopting this new positive approach that takes into account the particular features of public security, on the international plane the political forces on the left end of the ideological spectrum are accepting interpretations that I find important, interesting, enlightening but also one-sided and simplistic. I am referring to the theory according to which the contemporary concern with public security is complicit with neoliberalism. According to this view, because neoliberalism dismantled the protective nets of the welfare state and generated the poverty that is the source of crime, the security policy suited to it amounts to the criminalization of poverty and social exclusion through the unlimited expansion of imprisonment. Since in the U.S. this is indeed the situation Balmost two million people are already behind barsB every measure adopted by U.S. police forces are seen as no more than a functional adaptation to the sinister, malignant and repressive goals of neoliberalism. It follows that everything that is done outside of the U.S. but that responds to or incorporates the innovations introduced in American police forces is necessarily an attempt to 
reproduce the conditions for neoliberal colonization. Such a view makes it impossible to differentiate between "imprisonment policy" and what we might describe as the development of approaches to crime and police organization that converge with the resource to imprisonment only for contextual reasons, but which should not be seen as essentially complicit with such an orientation. The problem with this sort of analysis is that it encourages, in the progressive field, a return to "defensive" approaches, those that justify crime as a response to structural injustices and that discard from the outset any attempt to devise public-security policies, branding them as mere deviations from the only true and noble task, which is to act on the social causes of violence.

It is necessary to distinguish clearly between two moments, two levels or approaches: one is the emphasis on rigorous law enforcement, when the laws in question are compatible with human rights and express a democratic historical process; the other is the punitive drive, which defines offenders as the objects of revenge or as the targets of irrational, inhuman and counterproductive policies of imprisonment. It is possible to defend rigor in law enforcement, in the maintenance of the rule of law, by means of methods that are themselves legal and consistent with the respect for human rights, and at the same time to refuse imprisonment as a policy. Simplistic sloganeering about "neoliberalism, law-and-order and imprisonment policies" makes it impossible to appreciate the liberating and socially healing potential of a certain kind of legalistic rigor and strict adhesion to the democratic order in certain contexts. In the favelas of Rio de Janeiro, for example, to enforce law and order, with due respect to legal procedures Bwhich in the Brazilian case means respect for human rights $\mathbf{B}$ implies ensuring the most fundamental civic freedoms under the rule of law. Generalized criticism of law-and-order has the ultimate effect of blurring the line between those security policies that bring about the stabilization of positive expectations and the cruel and irrational repression of penitentiary systems. In order to break the vicious cycle of fear, anxiety, insecurity and self-fulfilling negative prophecies brought about by crime, it is sometimes necessary to resort to the authority of the police, which mobilizes the degree of force equivalent to the resistance against enforcement of the law, and which must submit to determinations derived from human rights if the process of affirming public order is to be legitimate. To provide the state with the requisite means to intervene when necessary and to provide society with mechanisms to preserve the democratic rule of law are popular and progressive requirements that have no necessary or preferential relation to repressive stands in the sphere of penalization. 
It is possible to aim at basic security for all, not excluding the control of violence and the reduction of crime, without subscribing to the socially discriminating and stigmatizing ideas and solutions of neoliberalism. On the other hand, the progressive sectors of society and the political leaders committed to radical democratization are courting disaster if they fail to show that they are capable of implementing their own law-and-order policy, understood as civil pacification under democratic legality and with respect for human rights. Progressive sectors are practically doomed to defeat if they accept the opposition between leniency and severity. To prove themselves ready to assume political control of society, progressives Bat least in BrazilB will have to discuss the meaning of severity and to replace the leniencyvs.-severity dichotomy with the question: What kind of severity are we talking about? Radical democrats should be in favor of severity, but of a kind that is rigorously subordinated to democratic laws and human rights, a severity that is generous, solidary, rational and constructive, restorative and integrating, resocializing and pacifying. Progressive democrats are likely to be more successful if they say: Our severity is better than the sort advocated by our conservative opponents because it leads to more effective results, has a better chance of allowing the resocialization of offenders and has a greater potential for imposing limits to crime and reducing its expansion.

Today, conceiving democracy as a process of building fairer and freer societies, exploring our rich theoretical traditions with an eye to going beyond them, implies $\mathrm{B}$ among other requirements $\mathbf{B}$ thinking critically about the unequal distribution of fear, anxiety and insecurity. If the public policies aiming at the democratic reduction of insecurity are not successful, fear and anxiety will tend to trigger violent popular reactions, stigmatizing discriminations, the defensive adoption of conservative institutional models and demands for authoritarian order. Therefore it will be imperative to associate creative and technically competent efforts that combine social, economic, cultural and public-security policies if we are to come close to our goal: basic security for all.

\section{Conclusion}

Considering the above mentioned points, which I interpreted on multiple levels in this paper, and taking into account its translation into empirical language, the following questions should be considered, if we want to include violence into the Latin American social research framework: 
(1) Main crimes per 100 thousand inhabitants: violent crimes/lethal crimes/ homicides.

(2) To what extent, if any, are "formal" democratic liberties limited by violence, by fear or its consequences? By formal liberties I mean: liberty of expression, organization, political participation, or just that one for coming and going.

(3) To what extent, if any, are social rights restricted? Here, I'm talking about access to public services, like schooling and health care.

(4) To what extent, if any, are usual or everyday decisions/choices or activities affected, taken or avoided, thanks to fear or caution or "presumed rational prediction"? I'm thinking on: (4.1) leisure (\&sports): going to soccer stadiums, to the beach, to the zoo, to the botanic garden, playing, jogging, etc...; (4.2) work; (4.3) dwelling (choosing neighborhoods for residence); (4.4) transportation or routing chosen; (4.5) public space frequency, as squares; (4.6) shopping; (4.7) consumption of cultural goods or services: going to movies, theatres, museums, seminars, exhibitions, bookstores.

(5) The key question of firearms, its availability and economic \& criminal dynamic, transforming the quality of violence and criminality.

(6) Domestic violence.

(7) Police credibility (Criminal Justice Institutions' credibility); (7.1) corruption; (7.2) brutality (usually combined with corruption and vice-versa); (7.3) ineffectiveness.

(8) Money laundry, corruption within the State, impunity (Political institutions credibility).

(9) Standards of victimization's distribution: age; ethnicity; neighborhoods; days and time; gender; class; education.

(10) Improvement or damage of expectations or personal projects (moving, hiring private security, planning careers, etc...).

(11) Patterns of crime organization and the dynamics of crime reproduction: recruitment of youngsters (which implies: double vulnerability of the poor families, since they loose their youngsters as victims and perpetrators as well as perpetrators, those youngsters will be targets of the Criminal Justice Institutions).

(12) Degree of politicization (I'm not just talking about terrorism, as a specific kind of violence, but also about the importance of violence within the public agenda, which implies its political importance, and therefore implies the nature of political investment on the issue and the quality of political treatment -the 
consequences may be, for instance, the increase of the social demand for authoritarian order, and the blockage of efforts to transform the whole situation through rational policies).

(13) Media, public agenda, elite's reactions towards "violence".

(14) Besides the Polices, the state of the Penal institutions.

(15) Public expenditure on violence's consequences and public policy's share in the State's budgeting.

Answering these questions could bring new light on the issue of violence; therefore, could bring new perspectives to social research on security and insecurity in Latin America. 